\title{
Adsorption studies of zinc(II) on magnetite, baobab (Adansonia digitata) and magnetite-baobab composite
}

\author{
N. Abdus-Salam ${ }^{1}$ · S. K. Adekola ${ }^{1}$
}

Received: 8 April 2016 / Accepted: 1 November 2018 / Published online: 12 November 2018

(c) The Author(s) 2018

\begin{abstract}
The negative effect of high concentration of heavy metals in the environment on living species prompted this research. A study of adsorption of zinc on synthesized magnetite (MG), baobab fruit shell (BB) and magnetite-baobab composite (MB) was carried out. The adsorption of $\mathrm{Zn}$ (II) ions was examined using batch equilibrium technique. The effects of initial metal ions concentrations ( $15-150 \mathrm{mg} / \mathrm{L}$ for zinc), adsorbent dose (0.05-0.3 g), contact time (5-150 min), $\mathrm{pH}(2-8)$ and temperature (303-343 K) on the sorption capacity of these adsorbents were investigated. The Zn(II) ions at a solution concentration of $150 \mathrm{mg} / \mathrm{g}$ gave maximum adsorption capacity of $38.25,33.95$ and $29.20 \mathrm{mg} / \mathrm{g}$ for MB, MG and BB, respectively. The adsorption of $\mathrm{Zn}$ (II) metal ions was modelled using Langmuir, Freundlich and Temkin isotherms. The highest correlation coefficient $\left(R^{2}\right)$ value was obtained from Freundlich model for Zn(II) adsorption on MG and MB as 0.986 and 0.973 , respectively, while that of $\mathrm{Zn}(\mathrm{II})$ on $\mathrm{BB}$ was obtained from Langmuir model as 0.993. The kinetic and thermodynamic studies revealed that the adsorption processes followed pseudo-second-order kinetics and were endothermic in nature. Desorption experiments were conducted on the spent adsorbent using $0.1,0.2,0.5,1.0$ and $2.0 \mathrm{M} \mathrm{HCl}$ to determine the reusability potentials of the adsorbents. There was an decrease in the amount of $\mathrm{Zn}$ (II) ions adsorbed after each stage of desorption process varied between the different acid concentrations. The $0.1 \mathrm{M} \mathrm{HCl}$ gave the highest degree of adsorption for $\mathrm{Zn}$ (II) on $\mathrm{BB}$, while $0.2 \mathrm{M} \mathrm{HCl}$ was the best for MG and MB.
\end{abstract}

Keywords Adsorption $\cdot$ Baobab $\cdot$ Biosorbent $\cdot$ Isotherm $\cdot$ Kinetic model $\cdot$ Composite

\section{Introduction}

Increase in industrial and mining activities has led to various deteriorations of the ecosystem and therefore poses dangers to human health and environment (Foo and Hammed 2010). Heavy metals are natural components of the earth's crust. They cannot be degraded or destroyed. To a small extent, they enter our bodies via food, drinking water and air. As trace elements, some heavy metals (e.g. copper, selenium, zinc) are essential to maintain the metabolism of the human body. However, at a high concentration, they can lead to poisoning. Heavy metal poisoning could result, for instance, from drinking water contamination (e.g. lead pipes), high ambient air concentrations near emission sources or intake via the food chain. Heavy metals are dangerous because they

N. Abdus-Salam

nasalami2002@yahoo.co.uk

1 Department of Chemistry, University of Ilorin, Ilorin, Nigeria tend to bioaccumulate in the body tissues for no known usefulness (Tangjuank et al. 2009). A high concentration of zinc has been observed in wastewaters from pharmaceutical, galvanizing, paint, pigment, insecticide and cosmetic industries. It has also been reported that zinc ions occur in the leachate of landfills at high concentrations. Low concentration of zinc is necessary for the growth of living systems, but it can easily bioaccumulate, which may become harmful to health once beyond the permissible limits.

With the increase in technological development and industrialization in our society, this consequently leads to an increase in the contamination of the environment through various means. Industrial waste, exhausts from factory engines and turbines, products of nuclear weapons among others lead to the release of some toxic heavy metals to our waters and air which also invariably have some complicated effects on the environment and human beings. Heavy metal contamination of water, air and soil regimes continued unabated despite several decontamination processes that have been developed. This makes research in process development 
with the synthesis of new adsorbent materials or modification of existing ones a necessity of recent time. Heavy metals are often discharged by a number of industrial processes, and this can lead to the contamination of freshwater and marine environment. Adsorption is one of the most effective and economic techniques for removing heavy metal ions from aqueous solutions. The efficiency of adsorption relies on the capability of the adsorbent to concentrate or adsorb metal ions from dilute solution onto its surfaces and the rate of removing such ions from the solutions. Different adsorbents such as activated carbon, zeolites, resins, biosorbents, hydrogel and magnetic hydrogel have been used for the removal of heavy metal ions by adsorption. Despite the availability of a number of adsorbents for the removal of low concentrations of heavy metal ions from the aqueous solution, there is still a need for the development of new adsorbent with superior adsorption capacity, facile adsorption-desorption kinetics, high stability and easiness of operation. Composite preparation is a growing area, particularly when low-cost materials of comparable adsorption capacities are involved. Magnetite is known for its good adsorption capacity for heavy metals but its synthesis is expensive for wastewater treatment; on the other hand, adsorption capacity of biomass adsorbents is relatively low. Preparation of composite from these two precursors will produce a new structural material with novel adsorption property. This informs the choice of our contribution to this area of adsorption process which focus on the use of magnetite, baobab and magnetite-baobab composite for $\mathrm{Zn}$ (II) removal from aqueous solutions.

\section{Materials and methods}

\section{Sample collection and preparation}

The baobab fruit shells (BFS) were obtained from University of Ilorin, Ilorin, Kwara State, and were rinsed with distilled water to remove dust and impurities deposited on the surface. The BFS were then air-dried and then oven-dried at $80^{\circ} \mathrm{C}$ to constant mass. The dried shells were pulverized and sieved to obtain particle sizes $\leq 300 \mu \mathrm{m}$. The baobab shell powder was soaked in $0.1 \mathrm{M} \mathrm{HNO}_{3}$ for $24 \mathrm{~h}$. Acid treatment was done to expose more ion binding sites. The mixture was filtered and the powder residue washed with distilled water several times until wash solution is neutral after which the filtered biomass was air-dried at ambient temperature. It was then pulverized and sieved below $90 \mu \mathrm{m}$ (Chigondo et al., 2013). All reagents that were used in this study were of analytical grade. Working standard solutions were prepared from analytical-grade reagents and by serial dilution method from the stock solutions. All synthetic procedures and characterizations for magnetite and magnetite-baobab composite were discussed in an article under review.

\section{Preparation of magnetite-baobab composite mixture}

A $80 \mathrm{~g}$ of $\mathrm{FeSO}_{4}$ was dissolved in $560 \mathrm{~mL}$ deionized water which has been previously flushed with $\mathrm{N}_{2}$. The 1-L glass reaction vessel $(1 \mathrm{~L})$ was closed with an airtight plastic lid having holes for insertion of $\mathrm{N}_{2}$ gas inlets and a thermometer. The reaction vessel was placed in a thermostat water bath at a temperature of $90^{\circ} \mathrm{C}$, a thermometer was inserted for temperature control, and a gas inlet for nitrogen purging. The whole reaction was carried out under nitrogen. Once the reaction temperature was reached, $240 \mathrm{~mL}$ of an oxygen-free solution containing $6.46 \mathrm{~g} \mathrm{KNO}_{3}$ and $44.9 \mathrm{~g} \mathrm{KOH}$ was added dropwise within approximately 5 min through a drop funnel. After the addition of this solution, it was heated for another 40 min (Cornell and Schwertmann 1996). Then, $11 \mathrm{~g}$ of baobab powder was added to the mixture, stirred and heated for another $10 \mathrm{~min}$ to produce magnetite-baobab ratio 2:1 composite mixture.

\section{Batch adsorption experiment}

Batch adsorption studies were performed by mixing $0.1 \mathrm{~g}$ each of the adsorbents (magnetite, baobab and magnetite-baobab composite) with a $25 \mathrm{~mL}$ of varying initial concentrations, $15-150 \mathrm{mg} / \mathrm{L} \mathrm{Zn(II)} \mathrm{ion} \mathrm{solutions} \mathrm{in} \mathrm{a} 100-\mathrm{mL}$ conical flask. The conical flasks were tightly covered during the equilibration period and placed on a temperature-controlled motorized orbital mechanical shaker (SHA-B Water Bath Temperature Oscillator) for a period of $5 \mathrm{~h}$ at $30^{\circ} \mathrm{C}$. After reaching adsorption equilibrium, the supernatant liquids were filtered and the un-adsorbed $\mathrm{Zn}$ ions in the filtrates were analysed by atomic spectrophotometry (AAS) (Salami and Adekola 2002). The quantities of $\mathrm{Zn}(\mathrm{II})$ adsorbed were calculated from Eq. (1) (Vibhawari and Pandey 2012; Adekola et al. 2011). The amount of $\mathrm{Zn}$ (II) ions adsorbed by magnetite, baobab and magnetite-baobab composite mixture was calculated separately based on the difference between the initial and final concentration of metal ion solution in every flask after specified period of shaking using Eq. 1:

$q_{\mathrm{e}}=\frac{C_{0}-C_{\mathrm{f}}}{M} \times V$

To express the per cent of each metal ion removed from the aqueous solutions by the adsorbents $\left(\% R_{\mathrm{em}}\right)$, the equation below was used (Abia and Asuquo 2006):

$\%$ rem $=\frac{\left(C_{0}-C_{\mathrm{f}}\right)}{C_{0}} \times 100$

where $q_{\mathrm{e}}$ is the quantity of metal adsorbed $(\mathrm{mg} / \mathrm{g}), C_{0}$ and $C_{\mathrm{f}}$ are the initial and final concentration of metal ion in 
solution at any time in $(\mathrm{mg} / \mathrm{L}), V$ is the total volume of the metal standard solution in the flask (L), and $\mathrm{M}$ is the mass of adsorbent used in ( $\mathrm{g})$.

\section{Equilibrium adsorption studies: effect of initial metal ion concentration}

A $25 \mathrm{~mL}$ of 15, 25, 50, 75, 100, $150 \mathrm{mg} / \mathrm{L} \mathrm{Zn(II)} \mathrm{solutions}$ were prepared by serial dilution of the stock solution and were contacted separately with $0.1 \mathrm{~g}$ of magnetite, baobab and magnetite-baobab composite mixture at $30{ }^{\circ} \mathrm{C}$ for $5 \mathrm{~h}$. At the end of $5 \mathrm{~h}$, the mixtures were filtered. The unadsorbed $\mathrm{Zn}$ (II) ions in the filtrate were analysed by AAS (Jimoh et al. 2012). The quantity adsorbed, $\mathrm{q}_{\mathrm{e}}$, was calculated from Eq. 1.

\section{Effect of contact time}

A $0.1 \mathrm{~g}$ of magnetite, baobab and magnetite-baobab composite mixture was weighed separately in 100-mL conical flasks. A $25 \mathrm{~mL}$ of the optimum concentration $(150 \mathrm{mg} / \mathrm{L}$ zinc) solution was added separately to each of the magnetite, baobab and magnetite-baobab mixture in the beaker. Each solution was agitated for different time interval of 5, 10, 15, $30,45,60,90,120$ and $150 \mathrm{~min}$ to investigate the effect of contact time. After the completion of the reaction, the mixtures were filtered and followed by the determination of the residual metal ion concentrations using AAS. The quantity adsorbed was calculated using Eq. (1) (Abdus-Salam and Itiola 2012).

\section{Effect of adsorbent dose}

The $\mathrm{Zn}$ (II) concentration that gave optimal adsorption per $0.1 \mathrm{~g}$ magnetite, baobab, magnetite-baobab composite mixture was used. A $25 \mathrm{~mL}$ of the $\mathrm{Zn}$ (II) solution was contacted with varying amounts of magnetite for $5 \mathrm{~min}$, baobab for $120 \mathrm{~min}$ and magnetite-baobab composite for $60 \mathrm{~min}(0.1$, $0.5,1.0,1.5$, and $2.0 \mathrm{~g}$ ) at laboratory temperature, $30^{\circ} \mathrm{C}$, and at the optimal concentration $[150 \mathrm{mg} / \mathrm{L} \mathrm{Zn} \mathrm{(II)].} \mathrm{The} \mathrm{mix-}$ tures were agitated with an orbital mechanical shaker model SHA-B Water Bath Constant Temperature Oscillator. At the completion of the contact, the solutions were filtered and the filtrate was analysed for $\mathrm{Zn}$ (II) using AAS (Abdus-Salam and Itiola 2012). The quantity adsorbed, $\mathrm{q}_{\mathrm{e}}$, was calculated from Eq. 1.

\section{Effect of temperature}

The temperature of the working solution was varied between 30 and $70{ }^{\circ} \mathrm{C}\left(30,40,50,60\right.$ and $\left.70{ }^{\circ} \mathrm{C}\right)$. A $25 \mathrm{~mL}$ of the optimum concentration, $150 \mathrm{mg} / \mathrm{L} \mathrm{Zn}(\mathrm{II})$, was contacted with $0.05 \mathrm{~g}$ of magnetite for $5 \mathrm{~min}, 0.1 \mathrm{~g}$ of baobab for
$120 \mathrm{~min}$ and $0.05 \mathrm{~g}$ of magnetite-baobab composite mixture for $90 \mathrm{~min}$ in 100-mL conical flasks. The mixtures were equilibrated at contact time at aforementioned temperatures. The mixtures were filtered, and the filtrates were analysed for $\mathrm{Zn}$ (II) using AAS spectrophotometer, and the quantities adsorbed were calculated by using Eq. (1) (Abdus-Salam and Itiola 2012).

\section{Effect of pH}

The effect of $\mathrm{pH}$ on $\mathrm{Zn}$ (II) adsorption was carried out over a $\mathrm{pH}$ range of 2-8. A $25 \mathrm{~mL}$ of the optimum concentration $150 \mathrm{mg} / \mathrm{L} \mathrm{Zn(II)} \mathrm{was} \mathrm{contacted} \mathrm{with} 0.05 \mathrm{~g}$ each of magnetite for $5 \mathrm{~min}$ and magnetite-baobab composite mixture for $90 \mathrm{~min}$ and $0.1 \mathrm{~g}$ of baobab for $120 \mathrm{~min}$ in $100-\mathrm{mL}$ conical flasks. The mixtures were equilibrated at contact time at $70{ }^{\circ} \mathrm{C}$. The mixtures were filtered, and the filtrates were analysed for $\mathrm{Zn}$ (II) using AAS. The quantity adsorbed was calculated from equation (Abdus-Salam and Itiola 2012).

\section{Results and discussion}

\section{Equilibrium studies: effect of initial metal ion concentration}

It was observed from Fig. 1 that the total amount of $\mathrm{Zn}$ (II) ions adsorbed per gram of the adsorbents (magnetite, baobab and magnetite-baobab composite) increased with increasing concentration while the percentage removal of the adsorbates reduced. Magnetite-baobab composite exhibited a higher adsorption capacity (mg/g) for $\mathrm{Zn}(\mathrm{II})$ compared to magnetite and baobab. Also, magnetite showed a higher adsorption capacity for both $\mathrm{Zn}$ (II) than baobab. At low concentration, the available driving force for transfer of metal ions onto the adsorbent particles is low, while at high concentration, there is a corresponding increase in the driving force, thereby enhancing the interaction between the

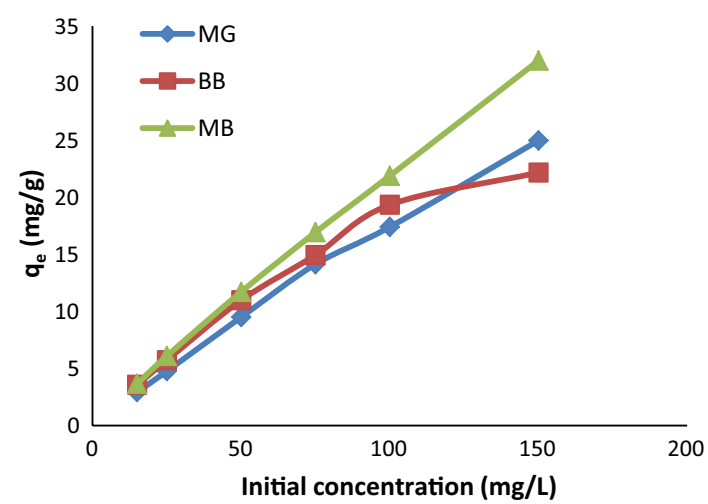

Fig. 1 Effect of concentration on adsorption of Zn(II)

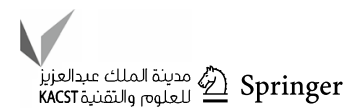


metal ions in the aqueous phase and the active sites of the adsorbents. As a result of this, there was an increase in the uptake of $\mathrm{Zn}(\mathrm{II})$ ions. Similar results were obtained on the monosorption of $\mathrm{Cu}, \mathrm{Pb}, \mathrm{Fe}, \mathrm{Cr}$ and $\mathrm{Cd}$ ions from aqueous solutions using coconut husk (Agbozu and Emoruwa 2014). A high metal concentration saturates the adsorbent sites more quickly, thereby decreasing the overall percentage metal removal (Yeddou and Bensmaili 2007). Therefore, there was an increase in the quantity of metal ions adsorbed $\left(q_{\mathrm{e}}\right)$ with an increase in the initial concentration, while the $\%$ removal was decreased which is the trend in a similar research (Andal and Sakthi 2010). Hence, the increasing value $q_{\mathrm{e}}$ is not directly proportional to the increasing initial concentration.

From Fig. 1, magnetite-baobab composite showed a higher adsorption capacity for Zn(II) with $31.97 \mathrm{mg} / \mathrm{g}$ in comparison with magnetite $(24.97 \mathrm{mg} / \mathrm{g})$ and baobab $(22.16 \mathrm{mg} / \mathrm{g})$. Therefore, it can be deduced from these plots that the adsorption capacity for the three adsorbents is in the order of magnetite-baobab (MB) > magnetite (MG) > baobab (BB) for both $\mathrm{Pb}$ (II) and $\mathrm{Zn}(\mathrm{II})$.

The influence of using varying amounts of adsorbents $(0.05-0.30 \mathrm{~g})$ while adsorbate initial concentration was fixed (Fig. 2) showed that as the adsorbent dosage was increased, the amount adsorbed also increased but the amount adsorbed per unit mass of the adsorbent decreased considerably for magnetite (MG), baobab (BB) and magnetite-baobab composite (MB). When the agitation speed and reactor size are kept constant after optimization of these parameters, increasing the adsorbent dose will reduce accessibility of adsorbate to the active sites on the adsorbent. The decrease in adsorption per unit mass with increasing dose of adsorbent is attributed to possible overlapping of adsorption sites as adsorbent dose increases or clogging of adsorbent which will equally reduce the effective adsorption sites. Concentration factor involving low metal-to-adsorbent ratio at low metal concentrations can be considered in explaining the dependence of adsorption on adsorbent dose. The percentage of metal ion adsorbed is dependent upon the initial concentration, and

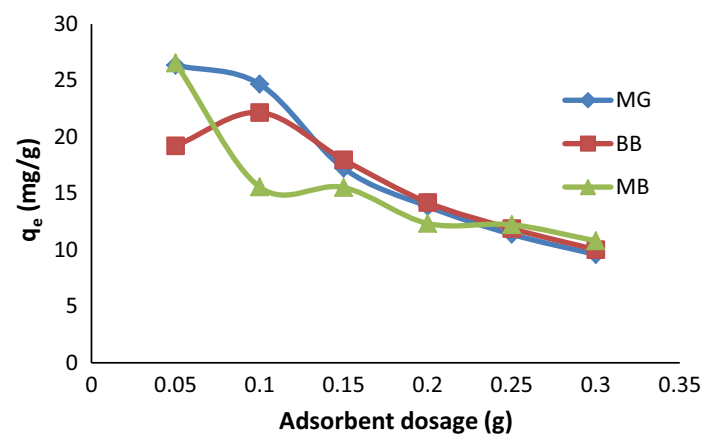

Fig. 2 Effect of adsorbent dosage on adsorption of $\mathrm{Zn}(\mathrm{II})$ at higher concentrations, the available sites of adsorption become fewer (Sekar et al. 2004: Gueu et al. 2006).

From Fig. 2, it was observed that as the adsorbents dose increased from 0.05 to $0.3 \mathrm{~g}$, the quantity adsorbed $(\mathrm{mg} / \mathrm{g})$ decreased from 26.35 to $9.59 \mathrm{mg} / \mathrm{g}$ for $\mathrm{Zn}$ (II) on $\mathrm{MG}$, $22.17-10.02 \mathrm{mg} / \mathrm{g}$ for $\mathrm{Zn}$ (II) on BB and $26.54-10.80 \mathrm{mg} / \mathrm{g}$ for $\mathrm{Zn}$ (II) on MB composite. This showed the high adsorption capacity of the magnetite and magnetite-baobab composite particles at low dosage. The biosorption of $\mathrm{Pb}(\mathrm{II})$ and $\mathrm{Zn}$ (II) from aqueous solution using Nordmann fir cones as the adsorbents (Yusuf et al. 2009) followed similar trend. Also, the influence of adsorbent concentration on adsorption of $\mathrm{Pb}$ and $\mathrm{Zn}$ on natural goethite (Abdus-Salam and Adekola 2005) followed this trend.

It is evident from Fig. 3 that MG showed rapid metal adsorption within $5 \mathrm{~min}$ of contact time due to the easy accessibility of the adsorption sites on the adsorbent and was followed by decrease/desorption of metals at longer contact times. The rate of adsorption indicated that the removal of $66.75 \%$ for $\mathrm{Zn}$ (II) was observed in the first $5 \mathrm{~min}$ of contact time. Some earlier reports had it that equilibrium time can be attained in a very short period for the removal of heavy metals on iron oxides reported (Jiang et al. 2013: Liliana and Juan 2013; Khodabakhshi et al. 2011). Furthermore, the rapid adsorption of $\mathrm{Zn}$ (II) by magnetite can be attributed to the external surface adsorption which is different from the microporous adsorption process which makes it easier for $\mathrm{Zn}$ (II) to access the active sites of magnetite readily resulting in rapid approach of equilibrium (Saidur 2013).

The effect of contact time on the biosorption of $\mathrm{Zn}$ (II) on BB showed that the amount of the adsorbed metal ions increases with increasing time till $120 \mathrm{~min}$ for $\mathrm{Zn}$ (II) with adsorption capacity of $22.48 \mathrm{mg} / \mathrm{g}$. Also, the equilibrium time for adsorption of $\mathrm{Zn}$ (II) on MB was 60 min with $26.86 \mathrm{mg} / \mathrm{g}$ adsorbed. A constant adsorption is indicative of equilibration due to saturation of adsorption sites. Rapid adsorption of metal ions during the initial stage was due to

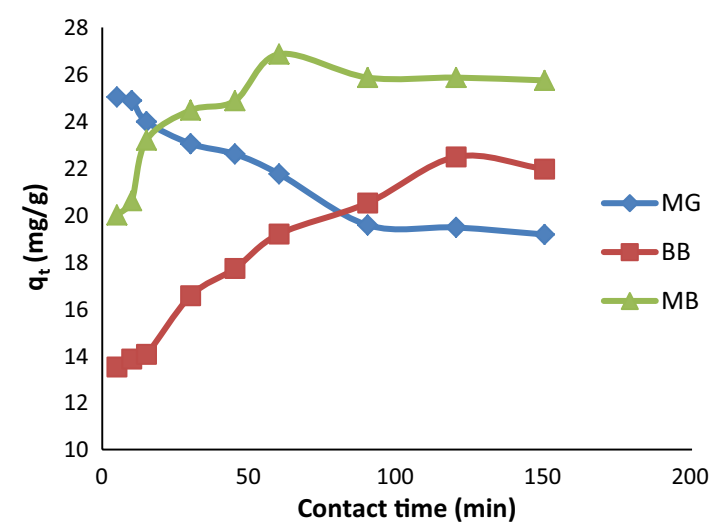

Fig. 3 Effect of contact time on adsorption of $\mathrm{Zn}$ (II) 


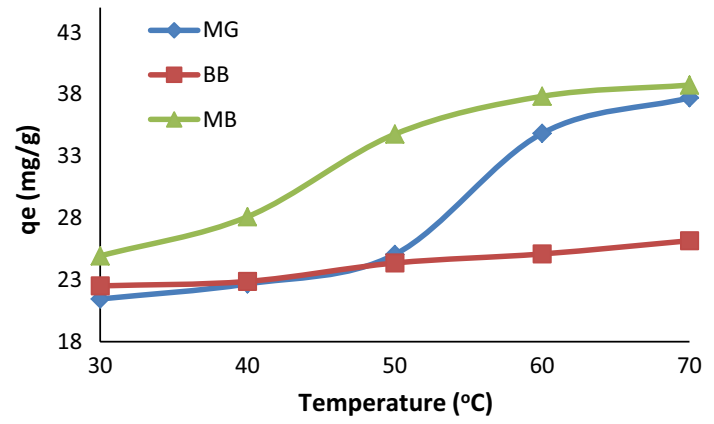

Fig. 4 Effect of temperature on the adsorption of $\mathrm{Zn}$ (II)

the large initial concentration gradient between the adsorbate in solution and the number of available vacant sites on the adsorbent surface (Chigondo et al. 2013).

\section{Effect of temperature}

It is observed from Fig. 4 that as the experimental temperature increases from 30 to $70{ }^{\circ} \mathrm{C}$, the $\mathrm{Zn}$ (II) adsorption also increased. For magnetite (MG), it increased from $28.60 \%$ at $30{ }^{\circ} \mathrm{C}$ to $50.27 \%$ at $70{ }^{\circ} \mathrm{C}$ for $\mathrm{Zn}$ (II). There were three stages of adsorption process as depicted by the curves: an initial slow $\left(30-50{ }^{\circ} \mathrm{C}\right)$, a fast $\left(50-60{ }^{\circ} \mathrm{C}\right)$ and a slow $\left(60-70{ }^{\circ} \mathrm{C}\right)$ increase in the adsorption given rise to an S-like curve. Also, for baobab (BB), there was a slight increase in adsorption uptake from $60.03 \%\left(30^{\circ} \mathrm{C}\right)$ to $69.75 \%\left(70{ }^{\circ} \mathrm{C}\right)$ for $\mathrm{Zn}(\mathrm{II})$. For $\mathrm{Zn}$ (II) adsorption on magnetite-baobab (MB) composite, the quantity adsorbed and the experimental temperature were directly proportional. The adsorption increased from $33.23 \%\left(30^{\circ} \mathrm{C}\right)$ to $51.65 \%\left(70^{\circ} \mathrm{C}\right)$ for $\mathrm{Zn}$ (II) with the S-like adsorption curve pattern similar to that of magnetite.

Generally, the increase suggests that the adsorption process is endothermic in nature. It also suggests that there were chemical interactions between the adsorbents and the metal ions in solutions. For ions to be adsorbed on the adsorbents, hydrated ions have to lose their hydrated shell, and this dehydration process needs energy which is compensated for by increase in temperature (Alvarez-Ayuso et al. 2003; Omar and Al-Itaw 2007; Babarinde and Babalola 2010; Castaldi et al. 2008). The removal of water molecules from hydrated ions is essentially an endothermic process. This increase is probably due to increase in the energy of the solution with increasing temperature which stimulated the diffusion of $\mathrm{Zn}$ (II) ions unto the adsorbent particles surface.

\section{Effect of pH}

From Fig. 5, it was observed that the percentage removal of $\mathrm{Zn}(\mathrm{II})$ ions in the aqueous solution was low at lower $\mathrm{pH}$ values and increased with increasing initial $\mathrm{pH}$ of the solution for MG, BB and MB adsorbents. The removal of

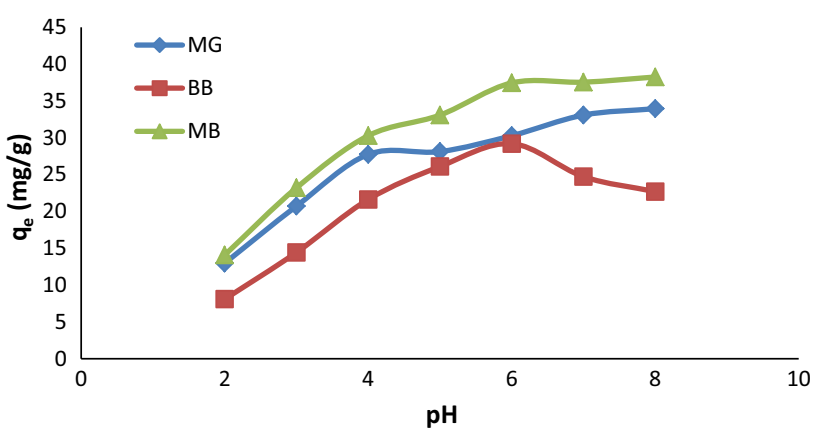

Fig. 5 Effect of $\mathrm{pH}$ on the adsorption of $\mathrm{Zn}$ (II)

$\mathrm{Zn}$ (II) by MG was about $90.98 \%$ at $\mathrm{pH} 8.0$ and $63.53 \%$ at a $\mathrm{pH}$ 2.0. Adsorption of $\mathrm{Zn}(\mathrm{II})$ onto MB followed a similar trend of which quantity adsorbed increased with an increase in the $\mathrm{pH}$ of the solution as observed from Fig. 5. At $\mathrm{pH}$ of $8.0,38.25 \mathrm{mg} / \mathrm{g}$ of $\mathrm{Zn}$ (II) was adsorbed as compared to $14.07 \mathrm{mg} / \mathrm{g}$ adsorbed at 2.0. It was observed that the maximum adsorption of $\mathrm{Zn}$ (II) on MG, BB and $\mathrm{MB}$ adsorbents occurred within the $\mathrm{pH}$ range 6-8. Increase in adsorption with $\mathrm{pH}$ increase may be due to the variation of surface charge of adsorbents as a function of $\mathrm{pH}$ of the solution. The dependence of metal sorption on $\mathrm{pH}$ is related to both the surface functional groups of the adsorbent and the metal ion chemistry in solution (Wang and Xing 2002) which gave rise to a S-like curves. The uptake and equilibrium adsorption capacity of metal removal from aqueous solution are strongly affected by the $\mathrm{pH}$ (Zvinowanda et al. 2009). The maximum adsorption of $\mathrm{Zn}$ (II) ions was achieved at $\mathrm{pH}$ 6. At $\mathrm{pH}$ higher than 6, both metal ions were precipitated. Therefore, the removal of metal ions at higher $\mathrm{pH}$ values greater than 6 was due to the formation of precipitates rather than adsorption (Bayat 2002). The adsorption capacity increased with an increase in $\mathrm{pH}$ up to $\mathrm{pH} 6$ for $\mathrm{Zn}(\mathrm{II})$. The increase in metal adsorption with an increase in $\mathrm{pH}$ is due to a decrease in competition between hydrogen ions and metal ions for the surface sites and also due to a decrease in positive surface charge. As the $\mathrm{pH}$ increases, more negatively charged surface becomes available and thus facilitates greater metal adsorption. At low $\mathrm{pH}$, the higher concentration and mobility of $\mathrm{H}^{+}$ ions favour its adsorption compared to metal ions. Metal ions are more soluble at lower $\mathrm{pH}$ values, and this reduces their adsorption (Onundi et al. 2010). Furthermore, at lower $\mathrm{pH}$, the surface of the adsorbent is surrounded by hydrogen ions $\left(\mathrm{H}^{+}\right)$thereby blocking metal ions from binding sites on baobab. A similar trend was observed in the studies of sorption of $\mathrm{Pb}$ (II) and $\mathrm{Cu}$ (II) onto magnetite eggshells- $\mathrm{Fe}_{3} \mathrm{O}_{4}$ powder (Ren et al. 2012) and removal of $\mathrm{Pt}^{2+}$ and $\mathrm{Au}^{3+}$ ions from aqueous solutions by magnetite nanoparticles (Liliana and Juan 2013).

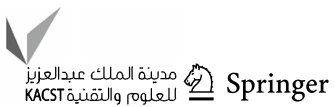




\section{Adsorption isotherm of $\mathrm{Zn}$ (II) ions on MG, BB and $\mathrm{MB}$}

The adsorption isotherm describes graphically how adsorbates interact with adsorbents, and this is important in the optimization of the use of adsorbents (Bulut and Aydin 2005). The equilibrium data were analysed using the Langmuir, Freundlich and Temkin isotherm models. High correlation value, $R^{2}$ (close or equal to 1 ), indicates the conformity among experimental data with model isotherm.

\section{Langmuir adsorption isotherm}

Figure 6 shows a plot of $C_{\mathrm{e}} / q_{\mathrm{e}}$ versus $C_{\mathrm{e}}$ from Eq. 3. Figure 9 represents the Langmuir isotherm behaviour for the adsorption of $\mathrm{Zn}$ (II) ion on magnetite, baobab and magnetite-baobab composite sample.

$\frac{c_{\mathrm{e}}}{q_{\mathrm{e}}}=\frac{1}{k_{\mathrm{L}} q_{\max }}+\frac{1}{q_{\max }} c_{\mathrm{e}}$

where $C_{\mathrm{e}}$ is the equilibrium concentration of the adsorbate $(\mathrm{mg} / \mathrm{L}), q_{\mathrm{e}}$ is the amount of adsorbate adsorbed per unit mass of adsorbate $(\mathrm{mg} / \mathrm{g}), K_{\mathrm{L}}$ is the Langmuir constant related to the energy of adsorption, and $q_{\max }$ is the maximum adsorption capacity $(\mathrm{mg} / \mathrm{g})$.

It can be deduced from the graphs using the correlation coefficient $\left(R^{2}\right)$ values that the experimental data for the BB fitted most into the model with 0.9932 followed by that of MG with 0.9506 and MB with 0.9145 for $\mathrm{Zn}(\mathrm{II})$ ion. The applicability of the Langmuir isotherm indicates good monolayer coverage of $\mathrm{Pb}(\mathrm{II})$ and $\mathrm{Zn}(\mathrm{II})$ ions on the surface of $\mathrm{MG}, \mathrm{BB}$ and $\mathrm{MB}$ which suggest the formation of a monolayer on the adsorbent surface in the given concentrations range (Alli and Muhammad 2008). The fact that the Langmuir isotherm fits the experimental data very well may be due to the homogenous distribution of active sites on the adsorbent since the Langmuir equation assumes that the surface is homogenous. The separation factor $R_{\mathrm{L}}$ for the

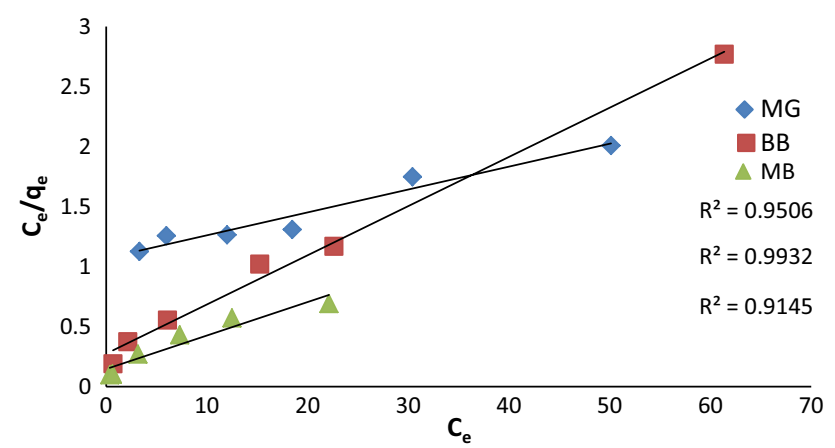

Fig. 6 Langmuir adsorption isotherm for $\mathrm{Zn}(\mathrm{II})$ isotherm can be used to predict the shape and the favourability condition of the adsorption process

$R_{\mathrm{L}}=\frac{1}{1+K_{\mathrm{L}} C_{0}}$

where $R_{\mathrm{L}}$ is the separation factor, $C_{0}$ is the initial concentration of $\mathrm{Zn}(\mathrm{II})$ ions $(\mathrm{mg} / \mathrm{L})$, and $K_{\mathrm{L}}$ is the Langmuir adsorption constant $(\mathrm{L} / \mathrm{mg})$. The result of the separation factor $\left(R_{\mathrm{L}}\right)$ presented in Table 1 from this research work showed that the values are within the range $\left(0<R_{\mathrm{L}}<1\right)$ which indicates that the adsorption of $\mathrm{Zn}(\mathrm{II})$ onto the three adsorbents is favourable.

\section{Freundlich adsorption isotherm}

The equilibrium concentrations of $\mathrm{Zn}$ (II) earlier obtained were subjected to Freundlich equation as shown in Eq. 5

$\log q_{\mathrm{e}}=\log K_{\mathrm{f}}+\left(\frac{1}{n}\right) \log C_{\mathrm{e}}$

where $q_{\mathrm{e}}$ is the amount of metal up take at equilibrium in $(\mathrm{mg} / \mathrm{g}), C_{\mathrm{e}}$ is the equilibrium adsorbate concentration in the bulk solution $(\mathrm{mg} / \mathrm{L}), k_{\mathrm{f}}$ and $n$ are Freundlich constants, $K_{\mathrm{f}}$ value is a measure of overall adsorption capacity of the adsorbent $(\mathrm{mg} / \mathrm{g})$, and $n$ is a measure of adsorption intensity. The plot of $\log q_{\mathrm{e}}$ versus $\log C_{\mathrm{e}}$ is shown in Fig. 7.

Comparing the correlation coefficient values for the adsorption of $\mathrm{Zn}$ (II) on the adsorbents (Fig. 7), the best fittings of data are in the descending order: $\mathrm{MG}>\mathrm{BB}=\mathrm{MB}$ with $R^{2}$ of magnetite being 0.986 , while both baobab and magnetite-baobab composites have the same $R^{2}$ value of 0.973 . The isotherm yielded a good linear plots having Freundlich adsorption intensity, $\mathrm{n}$, constant for $\mathrm{Zn}$ (II) on MG,

Table 1 Isotherm parameters for the adsorption of $\mathrm{Zn}$ (II) onto magnetite, baobab and magnetite-baobab

\begin{tabular}{lllll}
\hline Isotherms & Parameters & Adsorbents & \\
\cline { 3 - 5 } & & MG & BB & MB \\
\hline Langmuir & $q_{\mathrm{m}}$ & $52.63 \mathrm{mg} / \mathrm{g}$ & $24.39 \mathrm{mg} / \mathrm{g}$ & $37.04 \mathrm{mg} / \mathrm{g}$ \\
& $K_{\mathrm{L}}$ & $0.018 \mathrm{~L} / \mathrm{mg}$ & $0.15 \mathrm{~L} / \mathrm{mg}$ & $0.185 \mathrm{~L} / \mathrm{mg}$ \\
& $R_{\mathrm{L}}$ & $0.270 \mathrm{~L} / \mathrm{mg}$ & $0.0426 \mathrm{~L} / \mathrm{mg}$ & $0.0348 \mathrm{~L} / \mathrm{mg}$ \\
& $R^{2}$ & 0.950 & 0.993 & 0.914 \\
Freundlich & $n$ & 1.25 & 2.32 & 2.17 \\
& $1 / n$ & 0.798 & 0.431 & 0.461 \\
& $K_{\mathrm{F}}$ & $1.194 \mathrm{~L} / \mathrm{mg}$ & $4.436 \mathrm{~L} / \mathrm{mg}$ & $6.486 \mathrm{~L} / \mathrm{mg}$ \\
& $R^{2}$ & 0.986 & 0.973 & 0.973 \\
Temkin & $B$ & $7.978 \mathrm{~J} / \mathrm{mol}$ & $3.835 \mathrm{~J} / \mathrm{mol}$ & $7.802 \mathrm{~J} / \mathrm{mol}$ \\
& $b_{0}$ & $310.55 \mathrm{~J} / \mathrm{mol}$ & $560.156 \mathrm{~J} / \mathrm{mol}$ & $443.93 \mathrm{~J} / \mathrm{mol}$ \\
& $A$ & $0.3397 \mathrm{~L} / \mathrm{mg}$ & $2.380 \mathrm{~L} / \mathrm{mg}$ & $4.04 \mathrm{~L} / \mathrm{mg}$ \\
& $R^{2}$ & 0.955 & 0.967 & 0.862 \\
\hline
\end{tabular}




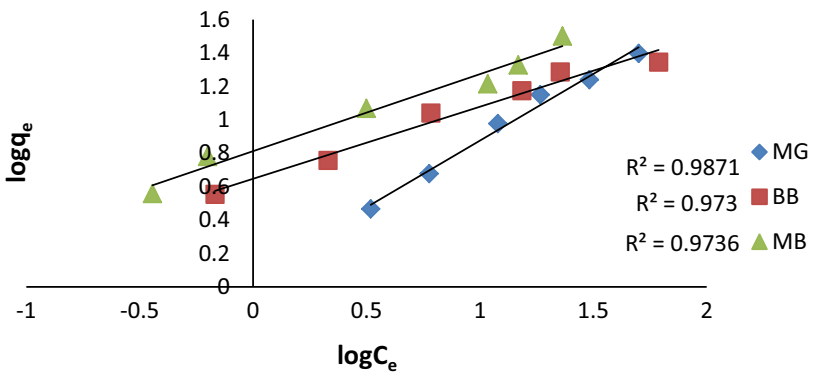

Fig. 7 Freundlich adsorption isotherm for $\mathrm{Zn}(\mathrm{II})$

BB and MB adsorbents as 1.253, 2.320 and 2.170, respectively. The $\mathrm{n}$ values predict whether the adsorption of a given ion is favourable or not. Since $n>1$ for adsorption of $\mathrm{Pb}$ (II) and $\mathrm{Zn}(\mathrm{II})$, the adsorption intensity is favourable at higher concentration (Adekola et al. 2011)].

\section{Temkin adsorption isotherm}

Figure 8 represents the Temkin isotherm behaviour for the adsorption of $\mathrm{Zn}$ (II) on magnetite, baobab and magnetite-baobab composite. The quantity adsorbed was calculated from Eq. 6. The plot of $q_{\mathrm{e}}$ versus In $C_{\mathrm{e}}$ gave the values of constants $A$ and $B$ as the intercept and slope of the curve, respectively.

$q_{\mathrm{e}}=B \ln A+B \ln C_{\mathrm{e}}$

where $A=$ Temkin isotherm equilibrium binding constant $(\mathrm{L} / \mathrm{g}), b_{0}=$ Temkin isotherm constant related to heat of adsorption $(\mathrm{J} / \mathrm{mol}), C_{\mathrm{e}}$ is the equilibrium solute concentration in the bulk solution $(\mathrm{mg} / \mathrm{L}), R=$ universal gas constant $(8.314 \mathrm{~J} / \mathrm{molK})$ and $T=$ temperature, and $B$ is a constant defined as $\frac{R T}{b_{0}}=B$.

The adsorption data obtained for $\mathrm{Zn}$ (II) on BB fitted best with correlation coefficient $\left(R^{2}\right)$ value of 0.967 , followed by 0.955 for MG and 0.862 for MB. The Temkin adsorption equilibrium binding energy constant, $\mathrm{A}$, for $\mathrm{MG}, \mathrm{BB}$ and

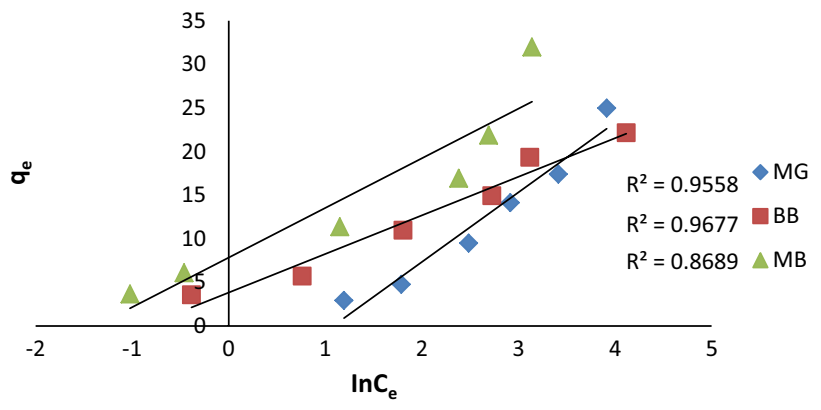

Fig. 8 Temkin adsorption isotherm on $\mathrm{Zn}$ (II)
MB composite is $0.3397 \mathrm{~L} / \mathrm{mg}, 2.380 \mathrm{~L} / \mathrm{mg}$ and $4.047 \mathrm{~L} / \mathrm{mg}$ for $\mathrm{Zn}$ (II) ions adsorption. This indicates that MB composite has higher adsorbent metal ion potential for $\mathrm{Zn}$ (II) followed by that of BB while MG has the least potential. The low values of $B B$ suggest that there is an indirect interaction among the particles of adsorbents and adsorbates which corresponds to the linear decrease in the heat of adsorption of all the molecules in the layer. Table 1 shows the isotherm model parameters for $\mathrm{Zn}(\mathrm{II})$ on the three adsorbents.

\section{Adsorption kinetics}

The kinetics of $\mathrm{Zn}(\mathrm{II})$ sorption onto $\mathrm{MG}, \mathrm{BB}$, and $\mathrm{MB}$ were investigated using pseudo-first-order and pseudo-secondorder kinetic models. The rate of $\mathrm{Zn}$ (II) adsorption on these adsorbents was described by these adsorption kinetics as a function of time. It helps to determine equilibrium time which gives useful information relating to the design of adsorption process and pollution flux (Abdus-Salam and Itiola 2012). The closeness of the experimental data and the model-predicted values were expressed by the correlation coefficient. A relatively high $R^{2}$ value implies that the model successfully illustrates the kinetics of $\mathrm{Zn}$ (II) adsorption.

\section{Pseudo-first-order kinetic model (Abdus-Salam and Itiola 2012)}

The rate constant values and amount of metal ions adsorbed are evaluated from the slope and intercept of Fig. 9 as described by linearized pseudo-first-order kinetic equation:

$\log \left(q_{\mathrm{e}}-q_{t}\right)=\log q_{\mathrm{e}}-\frac{k_{1} t}{2.303}$

where $q_{\mathrm{e}}$ and $q_{t}$ are the quantity of $\mathrm{Zn}$ (II) ions adsorbed $(\mathrm{mg} / \mathrm{g})$ at equilibrium and at any time $t$, respectively, and $k_{1}$ $\left(\mathrm{min}^{-1}\right)$ is the rate constant of the pseudo-first-order adsorption operation. Negative slopes were obtained in respect of plots of $\mathrm{Zn}$ (II) adsorption data for $\mathrm{BB}$ and $\mathrm{MB}$, while the $R^{2}$

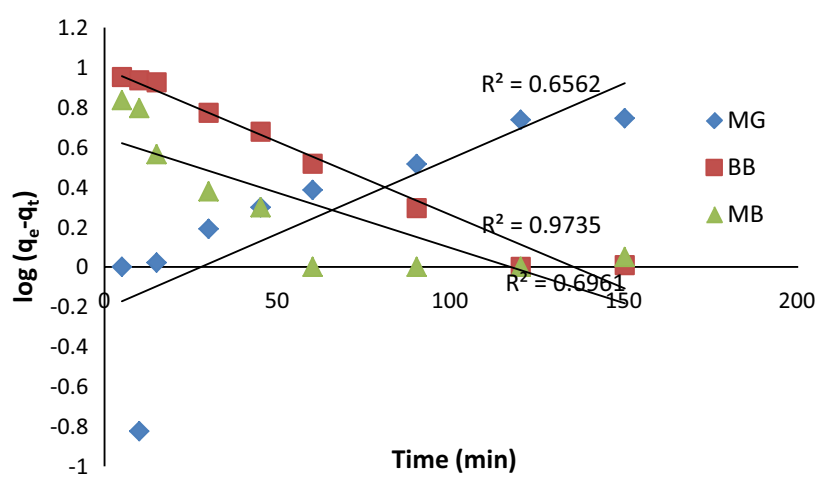

Fig. 9 Pseudo-first-order graph for adsorption of $\mathrm{Zn}$ (II)

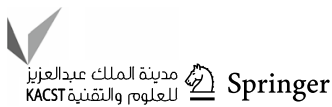


value for MG was low for practical application of the model. The $q_{\mathrm{e}}$ and $k_{1}$ obtained are summarized in Table 2 .

\section{Pseudo-second-order kinetic model}

Figure 10 shows the linear plot of pseudo-second-order model which describes the relative fitness of the model to experimental data for the adsorption of $\mathrm{Zn}$ (II) on the three adsorbents as described by simplified form of the pseudosecond-order equation (Abdus-Salam and Itiola 2012).

$\frac{t}{q_{t}}=\frac{1}{k_{2} q_{\mathrm{e}}^{2}}+\frac{1}{q_{\mathrm{e}}} t$

where $q_{\mathrm{e}}$ and $q_{t}$ are the quantity of metal ions adsorbed $(\mathrm{mg} / \mathrm{g})$ at equilibrium and any time $\mathrm{t}$, respectively, $k_{2}(\mathrm{~g} / \mathrm{mg} /$ $\mathrm{min}$ ) is the rate constant of the pseudo-second-order adsorption operation. The plot of $\frac{t}{q_{t}}$ versus t gives linear curve with $\frac{1}{q_{\mathrm{e}}}$ and $\frac{1}{k_{2} q_{\mathrm{e}}^{2}}$ as slope and intercept, respectively. This plot yielded good results with high correlation coefficient $R^{2}$ for $\mathrm{Zn}$ (II) (0.998) on MG, (0.994) on BB and (0.999) on MB indicating the best fittings of experimental data to pseudosecond-order model and described the adsorption process the best. The $q_{\mathrm{e}}$ and $k_{2}$ obtained are reported in Table 2 .

The pseudo-second-order adsorption kinetics equation is a better kinetics model than the pseudo-first-order kinetics equation, since it gave a better fit of experimental data with higher correlation coefficients compared to pseudo-first order. Similar behaviour was also reported on the synthetic magnetite nanoparticles applied to the removal of $\mathrm{Pt}^{2+}$ and $\mathrm{Au}^{2+}$ ions from aqueous solution (Liliana and Juan 2013) and removal of Zinc from aqueous solutions by magnetite silica core-shell nanoparticles (Emadi et al. 2013). Hence, on the basis of the excellent fitting of experimental data in the pseudo-second-order kinetic model and the correlation coefficient value $\left(R^{2}\right.$ close to 1 ), the main adsorption mechanism is probably a chemisorption reaction which may be the rate-limiting step. In chemisorptions, the heavy metals stick to the adsorbent surface forming a chemical (usually covalent) bond and tend to find sites that maximize their coordination with the surface (Atkins 1995).

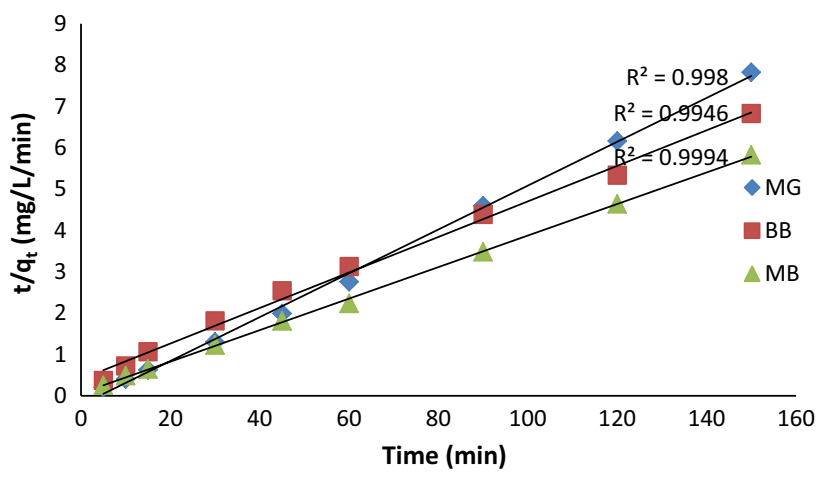

Fig. 10 Pseudo-second-order graph for adsorption of $\mathrm{Zn}$ (II)

\section{Adsorption thermodynamics}

Thermodynamic analysis was applied to the data obtained on the effect of temperature on adsorption. The thermodynamic parameters such as changes in Gibbs free energy $(\Delta G)$, enthalpy $(\Delta H)$ and entropy $(\Delta S)$ were determined from Eqs. (9, 10 and 11).

$K_{\mathrm{c}}=\frac{C_{A_{\mathrm{e}}}}{C_{\mathrm{e}}}$

$\Delta G^{\circ}=-R T \ln K_{\mathrm{c}}$

$\operatorname{In} K_{\mathrm{c}}=\frac{\Delta S^{\circ}}{R}-\frac{\Delta H^{\circ}}{R T}$

where $K_{\mathrm{c}}$ is the equilibrium constant, $C_{\mathrm{e}}$ is the equilibrium concentration of adsorbate in solution $(\mathrm{mg} / \mathrm{L})$, and $C_{\mathrm{Ae}}$ is the solid-phase concentration at equilibrium $(\mathrm{mg} / \mathrm{L}) . \Delta G^{\circ}, \Delta H^{\circ}$ and $\Delta S^{\circ}$ are changes in Gibbs free energy $(\mathrm{KJ} / \mathrm{mol})$, enthalpy $(\mathrm{KJ} / \mathrm{mol})$ and entropy $(\mathrm{J} / \mathrm{mol} / \mathrm{K})$, respectively; $R$ is the gas constant $(8.314 \mathrm{~J} / \mathrm{mol} / \mathrm{K})$; and $T$ is the temperature $(\mathrm{K})$. The values of $\Delta H$ and $\Delta S$ were, respectively, evaluated from the slope and intercept of the van't Hoff plot of $\operatorname{In} K_{\mathrm{c}}$ versus $1 / T$ (Eq. 11) as presented in Fig. 11. The thermodynamic parameters are summarized in Table 3.

From Table 3, the positive values of $\Delta \mathrm{H}$ that range from 9.26 to $21.17 \mathrm{~kJ} / \mathrm{mol}$ for $\mathrm{Zn}$ (II) onto the three adsorbents indicate that the reactions were physisorptions and endothermic in nature which implies an increase in adsorption
Table 2 Kinetic constants for $\mathrm{Zn}(\mathrm{II})$ adsorption

\begin{tabular}{llllllll}
\hline Adsorbent & \multicolumn{2}{l}{ Pseudo-first order for Zn(II) } & & \multicolumn{2}{l}{ Pseudo-second order for Zn(II) } \\
\cline { 2 - 3 } & $k_{1}\left(\mathrm{~min}^{-1}\right)$ & $q_{\mathrm{e}}(\mathrm{mg} / \mathrm{g})$ & $R^{2}$ & & $k_{2}(\mathrm{~g} / \mathrm{mg} / \mathrm{min})$ & $q_{\mathrm{e}}(\mathrm{mg} / \mathrm{g})$ & $R^{2}$ \\
\hline Magnetite & $1.612 \times 10^{-2}$ & 0.62 & 0.656 & & $1.28 \times 10^{-2}$ & 18.87 & 0.998 \\
Baobab & $1.612 \times 10^{-2}$ & 9.84 & 0.973 & & $4.60 \times 10^{-3}$ & 23.26 & 0.994 \\
Magnetite-baobab & 1.603 & 4.45 & 0.696 & & $2.29 \times 10^{-2}$ & 26.32 & 0.999 \\
\hline
\end{tabular}




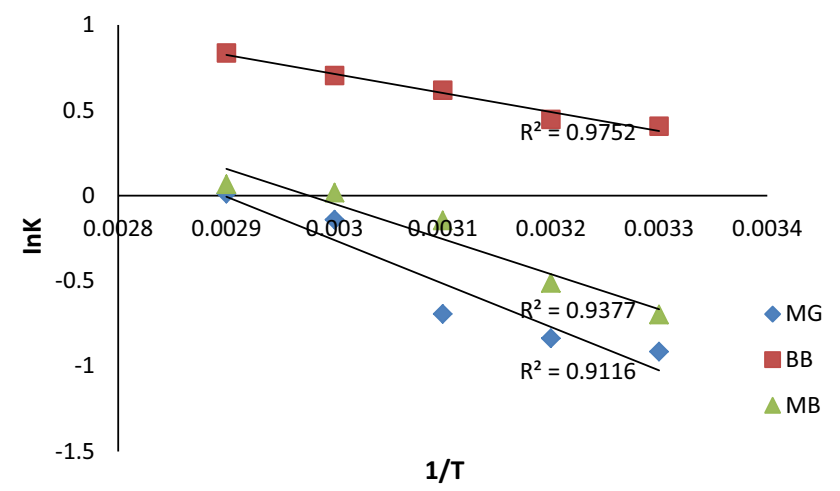

Fig. 11 van't Hoff graph for Zn(II) adsorption at different temperature

capacity with temperature increase. Adsorption is generally regarded to be physiosorption when the $\Delta \mathrm{H}$ value ranges between 2.1 and $20.9 \mathrm{~kJ} / \mathrm{mol}$ but chemisorption when $\Delta \mathrm{H}$ value ranges between 80 and $200 \mathrm{~kJ} / \mathrm{mol}$ (Liu and Liu 2008;
Abdus-Salam and Buhari 2016). The positive values of $\Delta \mathrm{S}$ which range from 33.73 to $61.33 \mathrm{~J} / \mathrm{K} / \mathrm{mol}$ for $\mathrm{Zn}$ (II) on the adsorbents suggest an increased randomness at the adsorbent-adsorbate interface during the fixation of the adsorbate ions on the active site of the adsorbent (Jain and Sharma 2002). The negative values of $\Delta G$ for the adsorption of $\mathrm{Zn}$ (II) on $\mathrm{Mg}$, BB and MB imply that the adsorption processes were feasible and spontaneous. Furthermore, the decrease in $\Delta G$ value with increasing adsorption temperature reveals that adsorption of $\mathrm{Zn}$ (II) onto the three adsorbents becomes better at higher temperatures.

\section{Desorption}

The data obtained from desorption experiment are plotted in Fig. 12a-c) to determine suitable leachant for regeneration and the reusability potential of the adsorbents (Abdus-Salam and Itiola 2012).
Table 3 Thermodynamic parameters for the adsorption of $\mathrm{Zn}(\mathrm{II})$

Fig. 12 Quantity of $\mathrm{Zn}$ (II) adsorbed $\left(q_{\mathrm{e}}\right)$ onto a MG versus desorption steps for various concentrations of $\mathrm{HCl}$, b BB versus desorption steps for various concentrations of $\mathrm{HCl}, \mathbf{c}$ $\mathrm{MB}$ versus desorption steps for various concentrations of $\mathrm{HCl}$

\begin{tabular}{lrlrrrrr}
\hline Adsorption & $\Delta H(\mathrm{KJ} / \mathrm{mol})$ & $\Delta S(\mathrm{KJ} / \mathrm{mol})$ & \multicolumn{2}{l}{$\Delta G(\mathrm{KJ} / \mathrm{mol})$} \\
\cline { 4 - 7 } & & & $303 \mathrm{~K}$ & $313 \mathrm{~K}$ & $323 \mathrm{~K}$ & $333 \mathrm{~K}$ & $343 \mathrm{~K}$ \\
\hline Zn(II) on MG & 21.17 & 61.33 & 2.30 & 2.18 & 1.86 & 0.39 & -0.03 \\
Zn(II) on BB & 9.26 & 33.73 & -1.02 & -1.16 & -1.66 & -1.95 & -2.38 \\
Zn(II) on MB & 17.09 & 50.89 & 1.76 & -1.33 & 0.39 & 0.05 & -0.19 \\
\hline
\end{tabular}

(b)
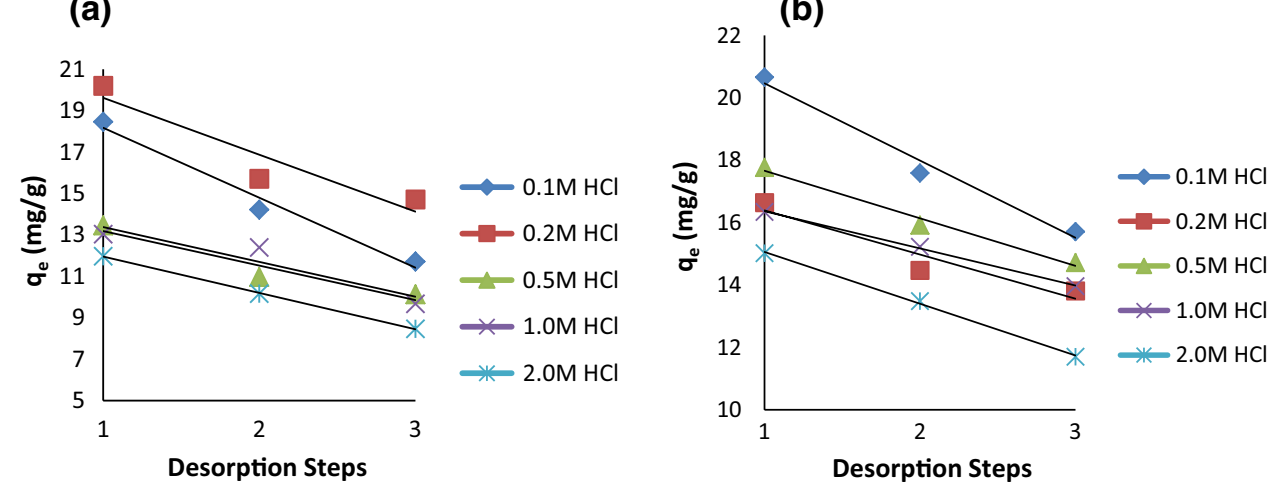

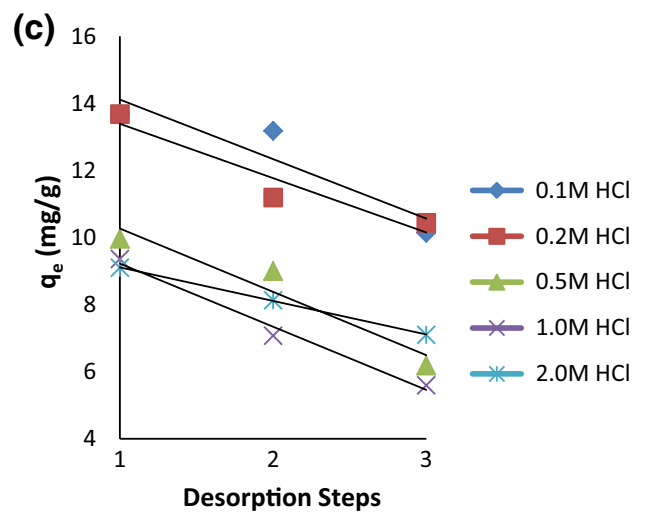


The initial conditions of the adsorbents (quantities of adsorbent and adsorbate to be desorbed) were the same before they were subjected to desorption experiment. It is observed from Fig. 12a-c that the quantities adsorbed after each step of desorption decreased with more steps of adsorption-desorption process. This might be due to the incomplete desorption of adsorbates which makes some adsorption sites not available during the subsequent adsorption. However, the results showed that the adsorbent has high potential of reusability. The $01 \mathrm{M} \mathrm{HCl} \mathrm{leachant} \mathrm{provided} \mathrm{the}$ best regeneration conditions for adsorption-desorption process for adsorption of $\mathrm{Zn}$ (II) on $\mathrm{MB}$ and BB. The stepwise adsorption of $\mathrm{Zn}(\mathrm{II})$ on $\mathrm{MB}$ is $87.86,71.87$ and $67.05 \%$, while on BB is $93.19,79.34$ and $70.86 \%$. The percentage $\mathrm{Zn}$ (II) adsorbed onto MG in the respective three steps of adsorption-desorption processes was the highest for $0.2 \mathrm{M}$ $\mathrm{HCl}$ stripping agent with $81.85,63.65$ and $59.60 \%$.

\section{Conclusion}

This study has demonstrated that the synthesized magnetite particles (MG), baobab fruit shells (BB) and magnetite-baobab composite (MB) have favourable properties for the adsorption of zinc(II) ions from aqueous solutions. The adsorbents were investigated on the effect of initial metal ion concentration, adsorbent dose, contact time, temperature and $\mathrm{pH}$ which are highly dependent on the efficiency of adsorption. The Langmuir, Freundlich and Temkin isotherm models were employed to describe the $\mathrm{Pb}$ (II) and $\mathrm{Zn}$ (II) adsorption onto the adsorbents of which Freundlich isotherm fitted the experimental data best with. The pseudo-secondorder kinetic model best-described the adsorption of $\mathrm{Zn}$ (II) on the adsorbents with $R^{2}$ value close to unity suggesting covalently bonded chemical process. Thermodynamic studies showed that the adsorption processes were endothermic and mostly spontaneous for $\mathrm{Zn}$ (II) on MG, BB and MB. The three adsorbents have also been found to have high efficiency for reuse at low concentrations of $\mathrm{HCl}$ leachant which suggests a good regenerative potential for the adsorbents usage.

Open Access This article is distributed under the terms of the Creative Commons Attribution 4.0 International License (http://creativeco mmons.org/licenses/by/4.0/), which permits unrestricted use, distribution, and reproduction in any medium, provided you give appropriate credit to the original author(s) and the source, provide a link to the Creative Commons license, and indicate if changes were made.

\section{References}

Abdus-Salam N, Adekola FA (2005) The influence of pH and adsorbent concentration on adsorption of lead and zinc on a natural goethite. Afr J Sci Technol 6(2):55-66
Abdus-Salam N, Buhari M (2016) Adsorption of alizarin and fluorescein dyes onto palm seeds activated carbon: kinetic and thermodynamic studies. J Chem Soc Pak 38(4):604-614

Abdus-Salam N, Itiola AD (2012) Potential application of termite mound for adsorption and removal of $\mathrm{Pb}$ (II) from aqueous solutions. J Chem Soc Niger 9:373-382

Abia AA, Asuquo ED (2006) Lead (II) and Nickel (I) adsorption kinetics from aqueous metal solutions using chemically modified and unmodified agricultural adsorbents. Afr J Biotechnol 5(16): 1475-1482

Adekola FA, Abdus-Salam N, Abdul-Rauf LB (2011) Removal of arsenic from aqueous solution by synthetic hematite. J Chem Soc Niger 36(2):52-58

Agbozu IE, Emoruwa FO (2014) Batch adsorption of heavy metals $(\mathrm{Cu}, \mathrm{Pb}, \mathrm{Fe}, \mathrm{Cr}$ and $\mathrm{Cd})$ from aqueous solutions using coconut husk. J Environ Sci 8(4):239-246

Alli H, Muhammad SK (2008) Biosorption of crystal violet from water on leaf biomass of Calotropis procera. J Environ Sci Technol 1(3):143-150

Alvarez-Ayuso E, Garcia-Sanchez A, Querol X (2003) Purification of metal electroplating waste waters using zeolites. Water Res 37(20):4855-4862

Andal NM, Sakthi V (2010) A comparative study on the sorption characteristics of $\mathrm{Pb}(\mathrm{II})$ and $\mathrm{Hg}(\mathrm{II})$ onto activated carbon. J Chem 7(3):967-974

Atkins PW (1995) Physical chemistry, 5th edn. Oxford University Press, New York, pp 122-124

Babarinde NA, Babalola JO (2010) The biosorption of $\mathrm{Pb}(\mathrm{II})$ from solution by elephant grass: kinetic equilibrium and thermodynamic studies. Pac J Sci Technol 11(1):622-630

Bayat B (2002) Comparative study of adsorption properties of Turkish fly ashes 1 . The case of nickel(II), copper(II) and zinc(II). J Hazard Mater 144:251-273

Bulut Y, Aydin H (2005) A kinetic and thermodynamic study of methylene blue adsorption on wheat shells. Desalination 194:259-267

Castaldi P, Santona L, Enzo S, Melis P (2008) Sorption process and XRD analysis of a zeolite. J Hazard Mater 156:428-434

Chigondo F, Nyamunda BC, Sithole SC, Gwatidzo L (2013) Removal of lead (II) and copper (II) ions from aqueous solution by baobab (Adononsia digitata) fruit shells biomass. IOSR J Appl Chem: IOSR-JAC 5(1):43-50

Cornell RM, Schwertmann U (1996) The iron oxides: structure, properties, reaction, occurrences and uses, 2nd edn. Wiley, New York, p 665

Emadi M, Shams E, Amini MK (2013) Removal of zinc from aqueous solutions by magnetite silica core-shell nanoparticles. J Environ Chem 5:1-10

Foo KY, Hammed BH (2010) Review: insight into the modelling of adsorption isotherm systems. Chem Eng J 156:2-10

Gueu S, Yao B, Adouby K, Ado G (2006) Heavy metals removal in aqueous solution by activated carbons prepared from coconut shell and seed shell of the palm tree. J Appl Sci 6(13):2789-2793

Jain CK, Sharma MK (2002) Adsorption of cadmium on bed sediments in river hindon: adsorption models and kinetics. Water Air Soil Pollut 137(1-4):1-19

Jiang W, Miguel P, Dionysios D, Mohammad HE, Dimitra T, Kevin O (2013) Chromium (VI) removal by maghemite nanoparticles. Chem Eng J 222:527-533

Jimoh TO, Buoro AT, Muriana M (2012) Utilization of Blighiasapida (Akee apple) pods in the removal of lead, cadmium and cobalt ions from aqueous solution. J Environ Chem Ecotoxicol 4(10):178-187

Khodabakhshi A, Amin MM, Mozaffari M (2011) Synthesis of magnetite nanoparticles and evaluation of its efficiency for arsenic removal from simulated industrial wastewater. Iran J Environ Health Sci Eng 8(3):189-200 
Liliana G, Juan CM (2013) Synthesis of Magnetite nanoparticles and exploring their application in their application in the removal of $\mathrm{Pt}^{2+}$ and $\mathrm{Au}^{3+}$ ions from aqueous solutions. Eur Chem Bull 2(7):445-452

Liu Y, Liu YJ (2008) Biosorption isotherms, kinetics and thermodynamics. Sep Purif Technol 61:229

Omar W, Al-Itaw H (2007) Removal of $\mathrm{Pb}^{2+}$ ions from aqueous solution by adsorption on kaolinite clay. Am J Appl Sci 4(7):502-507

Onundi YB, Mamun AA, Al Khatib MF, Ahmed YM (2010) Adsorption of copper, nickel and lead ions from synthetic semiconductor industrial wastewater by palm shell activated carbon. Int J Environ Sci Technol 7(4):751-758

Ren J, Bopape MF, Setshedi K, Kitinya JO, Onyango MS (2012) Sorption of $\mathrm{Pb}$ (II) and $\mathrm{Cu}(\mathrm{II})$ by low-cost magnetic eggshell- $\mathrm{Fe}_{3} \mathrm{O}_{4}$ powder. Chem Ind Chem Eng Q 18(2):221-231

Saidur C (2013) Application of mixed iron oxides in subsurface remediation technologies. A thesis submitted in partial fulfilment of the requirements for the degree of Doctor of philosophy, Department of Civil and Environmental Engineering, Western University London, Ontario, Canada, pp 78-309

Salami N, Adekola FA (2002) A study of Sorption of cadmium by geothite in aqueous solution. Bull Chem Soc Ethopia 16(1):1-7

Sekar M, Sakthi V, Rengaraj S (2004) Kinetics and equilibrium adsorption study of Lead(II) onto activated carbon prepared from coconut shell. J Colloid Interface Sci 279(2):307-313

Tangjuank S, Insuk N, Tontrakoon J, Udeye V (2009) Adsorption of lead(II) and cadmium(II) ions from aqueous solutions by adsorption on activated carbon prepared from cashew nut shells. World Acad Sci Eng Technol 6(2):298-306

Vibhawari, Pandey ND (2012) Single and competitive sorption of heavy metal ions of $\left(\mathrm{Cd}^{2+} \& \mathrm{Cu}^{2+}\right)$ on a clayey soil. E-J Chem 7(SI):S27-S34. https://doi.org/10.1155/2010/710546

Wang K, Xing B (2002) Adsorption and desorption of cadmium by goethite pretreated with phosphate. Chemosphere 48(7):665-670

Yeddou N, Bensmaili A (2007) Equilibrium and kinetic modelling of iron adsorption in eggshells in a batch system: effect of temperature. Desalination 206(1-3):127-134

Yusuf K, Ozkan A, Handan U (2009) Biosorption of Lead(II) and $\mathrm{Zn}$ (II) from aqueous solution by Nordmann fir Abies nordmanniana (Spach. Subsp. Nordmanniana) cones. Acta Chim Slov 56:451-456

Zvinowanda CM, Okonkwo OJ, Sekhula MM, Agyei NM, Sadiku R (2009) Application of maize tassel for the removal of $\mathrm{Pb}, \mathrm{Se}, \mathrm{sr}$, $\mathrm{U}$ and $\mathrm{V}$ from borehole water contaminated with mine wastewater in the presence of alkaline metals. J Hazard Mater 164:884-891

Publisher's Note Springer Nature remains neutral with regard to jurisdictional claims in published maps and institutional affiliations'. 